\title{
Romeral, una política de inclusion laboral: sostenible, con derechos y participación ciudadana.
}

Romeral, a labor inclusion policy: sustainable, with rights and citizen participation.

\author{
Yoselinne Aliaga F.* \\ Elena Reyes S.** \\ Enrique Espinoza**
}

Resumen: El presente trabajo tiene por objeto fortalecer la creación de una Política Pública Local para Personas en situación de discapacidad en la comuna de Romeral, utilizando los diversos enfoques en la participación ciudadana, además de una mirada centrada en el Modelo Social vinculando los Derechos Humanos de las Personas en Situación de Discapacidad (PsD). Es importante hacer énfasis en la creación de esta política, donde los actores tienen un papel importante el creación de esta, dando énfasis en la participación de las PsD para fortalecer y conocer desde su mirada las necesidades reales en alianza con otros actores, tanto políticos, públicos y privados. Para obtener como resultado la contribución de los actores, y que ello permita mejorar las condiciones de vida de las PsD, que se ven inmersas en el porcentaje de ciudadanos más pobres del país. Lograr esta propuesta de Política Local será de gran contribución a una comuna con mayores oportunidades y emprendimientos de las PsD, para generar oportunidades laborales que les permitan como trabajador y dignificación como sujetos de derechos en conjunto con la comunidad, y sus familias.

Palabras claves: participación ciudadana, discapacidad, inclusión e integración laboral, desarrollo local, ejercicio de derechos fundamentales.

Abstract: The present work aims to strengthen the creation of a Public Policy for People with local disabilities in the Romeral commune, using the various approaches in citizen participation, as well as a focus on the Social Model linking Human Rights of Persons with Disabilities (PsD). It is important to emphasize the creation of this policy, where the actors have an important role in the creation of it, emphasizing the participation of the $\mathrm{PsD}$ to strengthen and know from their perspective the real needs in alliance with other actors, both political, public and private. To obtain as a result the contribution of the actors, and that this allows improving the living conditions of the PsD, which are immersed in the percentage of poorest citizens of the country. Achieving this Local Policy proposal will make a great contribution to a commune with greater opportunities and enterprises of the PsD, to generate job opportunities that allow them as workers and dignity as subjects of rights in conjunction with the community, and their families.

\footnotetext{
* Trabajadora social Universidad Autónoma de Chile, yaliagaf@gmail.com

** Trabajadora social Universidad San Sebastián email e.v.reyes40@gmail.com

*** Contador Auditor Universidad Católica del Maule espinozaalegria@gmail.com
} 


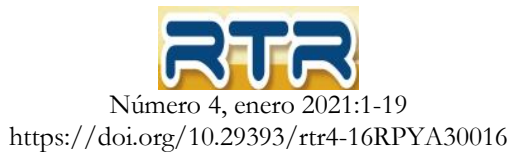

Keywords: citizen participation, disability, inclusion and labor integration, local development, exercise of fundamental rights.

Recibido: 22 octubre 2020 Aceptado: 12 diciembre 2020

\section{Introducción}

La comuna de Romeral se caracteriza grandemente por ser una zona agrícola, con extensas zonas de cultivos de fruta de temporada, además de lugares preciosos en su cordillera de los Andes, siendo un gran impulso en el desarrollo local, la exportación de berries, en especial la guinda, fruta que caracteriza la zona, haciendo posible abrir las puertas a un mercado internacional.

La zona además se caracteriza por cultivar sus raíces, costumbres, el folclor, y sus personajes típicos, como payadores, cantores, comidas y artesanía. Remozando las costumbres, con el objeto de mantener en el tiempo la cultura y la historia de esta bella comuna.

Como mencionamos anteriormente, la comuna en tiempos de temporada estival, mantiene su gran proceso de productividad agrícola y de cosecha en los campos, por lo que en este periodo de tiempo, es cuando aumenta en gran manera las funciones laborales.

Desde este punto, lo laboral, es que este equipo de trabajo ha querido proponer una política pública inclusiva, que vaya más allá de cumplir con las normativas legales de inclusión, como así lo estipulan la ley 21.015 y la ley 20.422 en temas laborales para persona en situación de discapacidad; por lo que replantear en el marco de los derechos de la personas con discapacidad (PsD) estimulando los ajustes razonables de los derechos fundamentales de las PsD, y promover una alianza política, publica, privada y social, para responder a las necesidades y responder al verdadero espíritu de los derechos universales de las PsD.

En la comuna existe un gran número de empresas procesadoras y exportadoras de fruta, quienes deben hacer cumplir la ley que los obliga a la contratación de PsD, con la cuota del 1\% por cada 100 trabajadores. Siendo un tema complejo en tiempo de producción, ya que las empresas priman por la productividad y dar cumplimiento a la ley, donde las empresas no están promoviendo un enfoque de política de inclusión sino más bien a una obligación a la contratación de recurso humano con alguna discapacidad leve o moderada que permita cumplir con la normativa y no con el verdadero trasfondo de la ley que quiere promover los derechos y sensibilizar a las empresas en abrir puestos de trabajo para PsD, que tengan un enfoque respectos de la igualdad y oportunidades.

La igualdad de oportunidades es el principio fundamental de justicia social que constituye la OIT, quienes promueven los ajustes razonables en temas de discapacidad y la inclusión en los lugares de trabajo.

La creación de esta política pública, no es una imposición a las empresas, al gobierno local y a la sociedad, sino más bien promover la diversidad y la inclusión como un derecho inherente, para contribuir a una mejor calidad de vida de las familias y de un mejor ambiente laboral en los puestos de trabajo, bajo la capacitación e información necesaria para conocer los derechos y deberes de las PsD ante la sociedad, con los debidos ajustes para lograr la integración de las PsD al mundo laboral más justo y necesario.

Lo importante en esta política pública, es potenciar las capacidades de las PsD, y dejar de enfocarnos en el asistencialismo y promover los derechos, ser partícipe de sus propias soluciones a tantos problemas que los aquejan, como uno de ellos, la pobreza o escaso ingreso de pensiones asistencialistas.

Por lo que, complementar los planes, programas y proyectos desde las áreas de lo público, implementadas por el Estado, permite dar una mirada real desde el enfoque de derecho y lograr 


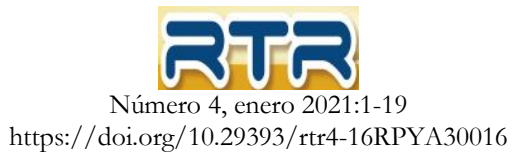

derribar las barreras de la discriminación, los prejuicios y estigmas, en relación a las $\mathrm{PsD}$, barreras que la sociedad no ha logrado derribar.

Por lo que el interés de este equipo, es contribuir a una comuna más inclusiva desde el ámbito laboral, donde los actores son la base para la creación y elaboración de esta política, con mejores condiciones de vida familiar y la disminución de la vulnerabilidad a las personas en situación de discapacidad.

Con este impulso, el poder crear una mesa de trabajo estratégico con la empresas de la zona, además de instituciones que aporten a la capacitación tanto para las $\mathrm{PsD}$, como para el equipo de trabajo, así también de lograr a través de esta alianza una cooperativa, que pueda entregar servicios a las mismas empresas, permitirá, otorgar mayores puestos de trabajo; más bien, una oportunidad laboral que dignifique a las PsD.

Al utilizar el lema "nada sobre nosotros, sin nosotros", claramente muestra que el actor principal son las PsD, para una participación plena en sus derechos, más que de una forma representativa, sino participativa y radical, donde lo que ellos comuniquen sea de gran aporte a cumplir con el desarrollo personal a una vida independiente, como el aporte al desarrollo local y el cambio sesgado de lo que es hoy la discapacidad.

\section{Desarrollo}

"Desde la perspectiva de las políticas públicas la falta de autonomía es abordada en diversas formas... derivado de según la predominación de un enfoque asistencial o de derechos, los que contienen dos miradas contrapuestas,... visualizando PsD como receptores de beneficios, es decir objeto de política pública y en cambio en otra la segunda perspectiva se les visualiza como sujeto de derecho, que nos implica ser receptores de beneficios sociales, sino que pueden participar en las soluciones a los problemas sociales que les aquejan.” (Gutiérrez, Farías, 2016, p.4)

\section{Diagnostico Comunal}

Romeral es una comuna ubicada en el centro sur de Chile, en la región del Maule, actualmente posee una población de 15.122 habitantes según el censo 2017 y con una gran proyección del 19,1\% en aumento. Se caracteriza por tener una gran superficie rural, mayor a la urbana, limitando con Argentina en su cordillera de los Andes. Su distribución de superficie es de 1597,1 $\mathrm{km}^{2}$ con una densidad de 9,509 $\mathrm{hab} / \mathrm{km}^{2}$.

En cuanto a los habitantes, en Chile según el II Estudio Nacional de Discapacidad (ENDIS), existe un porcentaje del $16 \%$ de la población que tiene alguna discapacidad, lo que lleva a 2 millones 836 mil 818 personas, según el CENSO año 2017. (SENADIS)

La región del Maule en comparación con otras regiones y según la densidad de sus habitantes es una de las comunas con mayor porcentaje de $\mathrm{PsD}$, como lo presenta el gráfico a nivel regional creado por el ENDIS. Primeramente es la región de Arica y Parinacota, luego la subsede la región de los Ríos y posteriormente la región del Maule. 


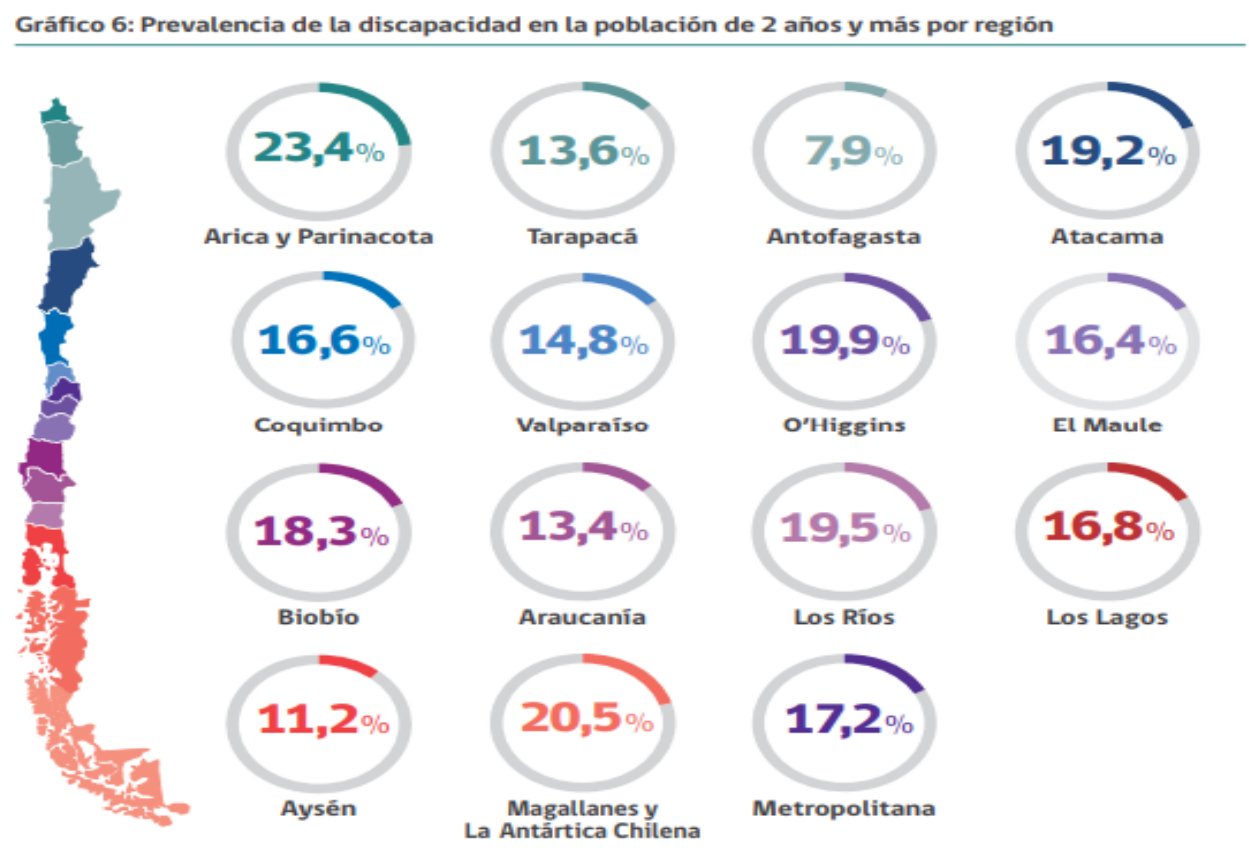

Ilustración 1/l Estudio de Discapacidad 2015

En Romeral, no existe una estadistica exacta respecto de la población de personas en situación de discapacidad en concreto. Según el registro Social de hogares, las PsD son de 116 (ciento dieciseis) aporximadamente, pero no concuerda con los registros que mantiene la oficina de discapacidad desde su creación en el año 2015, cuando comenzaron a realizar las acreditaciones para pertenecer al Registro Nacional de PsD, siendo a la fecha 357 (trecientas cincuenta y siete personas) quienes cuentan con la acreditación. Cabe señalar, que aún existen personas que no cuentan con su credencial por lo tanto, no se concoe un número exacto que pueda dar a conocer la población de PsD en la comuna. La comuna, no cuenta con un censo propio que pueda entregar datos fidedignos del total de PsD, su condición, su estatus, entre otros datos que son de importancia contar para poder lograr una política que indique $\mathrm{u} / 0$ entregue la realidad de la comuna en cuanto a número de PsD.

La oficina comunal de discapacidad, es unipersonal, por lo que actualmente no cuenta con las competencias y el personal adecuado para poder cumplir con el lineamiento de la Estrategia de Desarrollo Local Inclusivo (EDLI) que fue implementada como plan piloto en el año 2015, para impulsar la gestión en la comuna, no obteniendo el impulso y seguimiento y con la finalidad de la promoción y vinculación de la sociedad y el sistema empresarial en un trabajo en conjunto. Posteriormente queda en la gestión administrativa comunal, y si bien existe el interés político, no cuenta hoy en día con la capacidad financiera que permita dar con la continuidad de la política pública. Lo que sí, cabe destacar que al realizar este proyecto, se logró implementar una sala de Rehabilitación en el CESFAM de la comuna que cuenta con los profesionales pertinentes, para la atención de las PsD, que asisten en su primer proceso de rehabilitación.

La EDLI buscaba impulsar la transversalización de una gestión inclusiva en todos sus departamentos y fortalecer como actor clave al municipio ante otros actores locales, con el fin de dar respuesta a las necesidades de las PsD de la comuna (Buenas Prácticas inclusivas 2017-2018)

Esta descontinuación, hizo retroceder los procesos y no avanzar en materia de inclusión laboral. 
La discapacidad en Chile comprende distintas dimensiones, están pueden ser físicas o psíquicas las cuales son muy heterogéneas, ya que una discapacidad en un sujeto se desarrolla distintamente que en otro individuo. Las dificultades de carácter físico, tienen relación con problemas en el funcionamiento del cuerpo humano, y algunas de ellas pueden ser adquiridas, temporales o pueden ser dadas desde el nacimiento.

Para Padilla, "el termino discapacidad significa una deficiencia física, mental o sensorial, ya sea de naturaleza permanente o temporal, que limita la capacidad de ejercer una o más actividades esenciales de la vida diaria, que puede ser causada o agravada por el entorno económico y social" (p, 401)

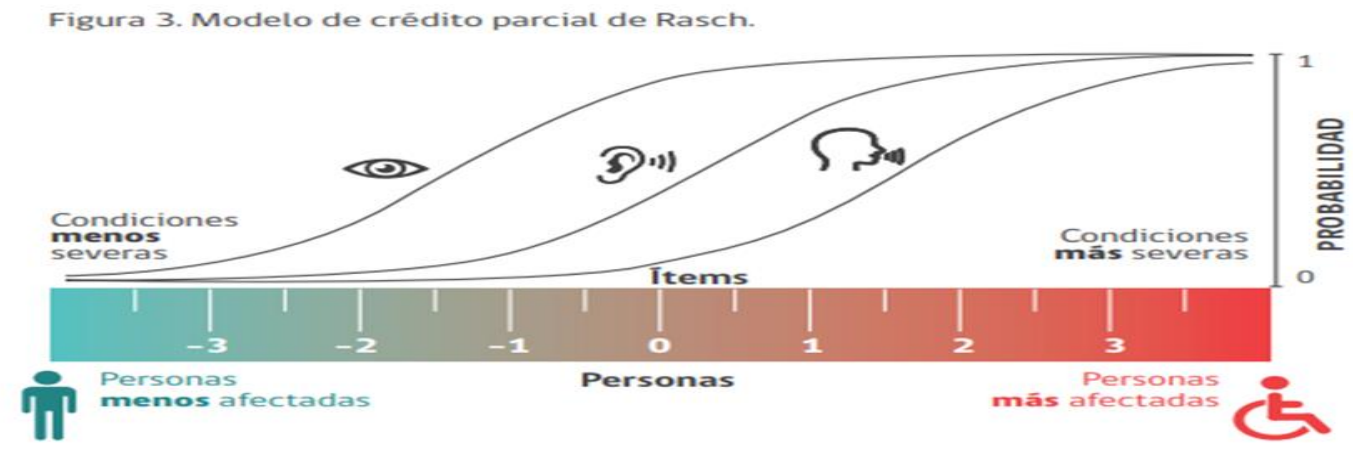

Fuente: Adaptacion de acuerdo a la dificultad obtenida en la metrica de capacidad en el ENDISC II en base a la figura de la página 303 del documento "Barnett, $C$., Merkies, 1., Katzberg. H., Bril, V. (2015) Psychometric Properties of the Quantitative Myasthenia Gravis Score and the Myasthenia, Gravis Composite Scale. Journal of Neuromuscular Diseases 2.

Ilustración 2II Estudio de Discapacidad 2015

\section{La Discapacidad}

El planteamiento de una nueva cultura de la discapacidad parte de la interacción entre la persona y el ambiente donde vive, y si se apoya fundamentalmente en concepción de la propia capacidad, de sus intereses y de la capacidad de elegir. El contexto cultural permite que el sujeto pueda adaptarse al sistema o entorno que le rodea, permitiendo generar sus propias capacidades para aprender a convivir con un entorno ajeno a sus requerimientos. Es por lo que sus redes son importantes para enfrentar la sociedad con estereotipos y constructos que hacen ver y sentir a los sujetos como seres ajenos a su entorno.

Desde un punto de vista social, hay que tener en cuenta, el contrario, que la discapacidad y minusvalía se derivan de un patrón cultural según el cual las actividades humanas se entienden como aquellas que llevan.

Las consecuencias inevitables de ello es que, en tanto que fenómeno social muy distante de una simple resultante mecánica de una afección fisiológica, la discapacidad, los sujetos están insertos en un mundo que no los integra, todo está hecho y pensado para satisfacer las necesidades de personas "normales", donde primeramente deberían ser satisfechos los intereses de las personas con discapacidad por sobre las personas no discapacitadas. Se trata del sentido cultural de los seres humanos que otorgamos al comportamiento según categorías sociales que tenemos preexistentes.

Muyor Rodríguez (2011) señala que las personas en situación de discapacidad se presentan como un instrumento jurídico vinculante a la hora de ejercer los derechos de ellos. Este tratado desde un modelo social centrado en el derecho, plantea una intervención crítica de las estructuras sociales que 


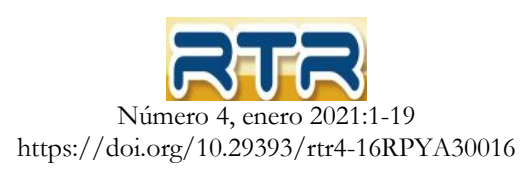

limitan a las personas con discapacidad y las excluye socialmente. Por lo que apostar a este modelo, aporta al colectivo de estos sujetos, integrando la "perspectiva de derechos humanos como punto de partida y llegada...l”. (pág., 9)

Antes de llegar al modelo social centrado en los derechos, la discapacidad viajó por diversos modelos teóricos que la fundamentaban, como:

Modelo de la prescindencia, que refiere a la antigüedad donde el motivo de la discapacidad era religioso siendo estas personas una carga para la sociedad. Modelo médico- rehabilitador, que alude a la discapacidad en términos de salud o ausencia de enfermedad, este surge luego de la segunda guerra mundial, siendo sujetos de caridad y objetos médicos. Modelo social, es aquel que no considera las dos causas anteriores, sino que son sociales y que se encuentran diseñadas en la sociedad. (Ibid, p, 12-13)

Este último hace referencia que las limitaciones no son de los individuos si no el problema es la sociedad que coloca límites para entregar servicios apropiados y que las personas en situación de discapacidad y sus necesidades sean consideradas, por lo que niega el individualismo pasando a un contexto social, de manera que el pensamiento y diseño sean para atender las necesidades de todos sin distinción y que permita brindar igualdad de oportunidades. (Ibid, p, 13-14)

Desde el modelo social basado en los Derecho de las personas en situación de discapacidad, La Convención señala que cuyo propósito es "promover, proteger y asegurar el goce pleno y en condiciones de igualdad de todos los derechos humanos y libertades fundamentales por todas las personas con discapacidad, y promover el respeto a su dignidad inherente" art. 1 de la convención (Padilla, 2010 pág., 390)

Por lo que la Convención Internacional sobre los Derechos de las Personas con Discapacidad, ratificada también por nuestro país (2008), atañe a la forma de abordar la discapacidad, como derechos humanos, donde las personas no son "objeto" sino "sujetos" de derecho. De tal manera que, se promueve la dignidad y autonomía, no discriminación, participación e inclusión, respeto y aceptar la discapacidad como parte de la diversidad humana, igualdad de oportunidades, accesibilidad, así también igual entre hombres y mujeres. (Muyor Rodríguez, 2011, pág., 22)

Con esto constituye un paradigma de protección jurídica para esta población, como reflejo del momento real de la diversidad y el reconocimiento de la diferencia en la historia. Además señalar que este tratado es el primero en la historia en ser vinculante. Así también, proponer desde esta lógica que la discapacidad en un modelo social centrado en el derecho, permite contribuir en conjunto con la interacción con los sujetos, logrando incluir la percepción a través de la participación e integración. De este modo, los sujetos se ven representados por él, o por quienes gobiernan, ya sean de manera central o local

Así también Muyor (2011) señala que desde "el foro vida independiente se realiza un "giro epistemológico" que propone el uso del nuevo término "diversidad funcional", como sustitutivo de los peyorativos "discapacidad, minusvalía, invalidez", tradicionalmente utilizados para designar al colectivo. De esta manera la persona puede encontrar una identidad que no sea percibida como negativa" (pág., 15)

El poder lograr cambios significativos para les personas con diversidad funcional, se hace necesaria, desde el apoyo positivo para la intervención con el colectivo y centrar los requerimientos a cambios en curso, en las modalidades particulares de la comunicación y de relación entre los sujetos, sino enfatizar y potencial de manera dinámica enfocando siempre lo positivo que constituya un cambio radical a la aproximación de una política de inclusión laboral.

Es por eso que debemos ser optimistas y valorar los pequeños cambios, para lograr articular entre los sujetos, comunidad social, una alianza socioeconómica, para promover desde una mirada holística e integral, las potencialidades de las personas y sus recursos existentes, logrando realizarse y donde ellos sean personas observadas como agentes activos con grandes potencialidades y no como meros receptores de caridad. 


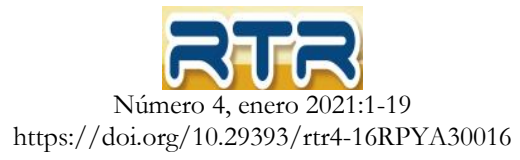

\section{Gobierno y desarrollo Local}

El gobierno local debe abordar las necesidades de desarrollo social de sus ciudadanos, como brindar salud, educación vivienda y accesos a servicios básicos, sin dejar de lado la cultura y la recreación, siendo necesarios y esenciales para la calidad de vida en el territorio. De la misma manera permiten vigilar y promover medidas que ayuden al desarrollo sostenible del territorio mismo. Junto con el desarrollo social y sostenible, los gobiernos locales se ocupan por el desarrollo económico, por el acceso al empleo decente y digno de sus habitantes, como garantía del arraigo de la población a su territorito.

Según los registros de DataChile, Romeral ha establecido al año 2016 una exportación de US\$ 78,15 millones, durante los últimos años, existiendo un crecimiento a una tasa promedio del $18 \%$ desde el 2011 al 2016, las principales exportaciones son a países como Estados Unidos y China, en frutas, lo que representa un $52 \%$ de las exportaciones de la las empresas de la comuna.

Dentro de estos procesos de desarrollo local, juega un papel importante los Gobiernos Locales, quien apoyan a impulsar las medidas de sostenibilidad dentro del territorio, donde un punto impórtate es el desarrollo sostenible, equiparado junto al desarrollo económico, lo que permite pretender a empleos decentes y dignos.

El municipio contempla una gran innovación en acciones de desarrollo, siendo su fortaleza el mismo como agente autónomo para resolver su estructura y asignación de recursos. Muchas de estas ofertas que se ha incorporado son motivadas por el sector público como Servicio Nacional de Discapacidad (SENADIS), Subsecretaria de Desarrollo Regional (SUBDERE), Ministerio Desarrollo Social (MDS), Ministerio de Salud (MINSAL), entre otros, como organismos no gubernamentales, quienes coordinan con los municipios la implementación de programas y asistencia técnica.

El accionar de los municipios varía según los diversos factores, como inequidad y diversidad en el territorio, donde los actores claves deben contar con voluntad política, un equipo municipal capacitado y una cultura local inclusiva a nivel sociocomunitario.

Valenzuela (1996) señala que "Los territorios locales necesitan un gobierno efectivo y que el sentido de su acción esté influido por la comunidad, especialmente en función del desarrollo de las capas más marginadas. Por tanto, se produce un doble desafío: lograr superar los límites de los municipios haciendo que los mismos encabecen redes de gobierno con otras instituciones públicas y de la sociedad civil, y a su vez, lograr que la comunidad organizada pueda influir en esas decisiones, evitando que las orientaciones apunten sólo a los intereses de los grupos más poderosos que tienen mayor influencia en las "decisiones de gobierno" (p.1)

El Fondo Andaluz de Municipalidades para la solidaridad internacional (FAMSI, 2016) señala que las instituciones públicas deben ser cercanas a la gente de su territorio, para conocer los problemas de la comunidad. El conocer estos antecedentes permite que el gobierno local convoque interesados o actores claves de la economía local. Actores que serán relevantes a la hora de crear la política pública local, y hacerlo participes con alianza para el desarrollo colaborativo.

Estos representantes como cámara de comercio, representantes de Las PYMES, productores, instituciones de capacitación, otros agentes de gobierno, la comunidad y quienes se encuentran marginados, entre ellos las PsD, son quienes deben iniciar y conducir los procesos de involucramiento para nuevas estrategias de desarrollo económico local. Por lo que la asociatividad donde todos cumplan un rol fundamental, puede lograr ser depositarios de mejores prácticas que sean de impacto en la comunidad. Con esto fomentar y crear puestos de trabajos acordes y fomentar el bienestar.

"El desarrollo local aparece como una nueva forma de mirar y de actuar desde lo local en este nuevo contexto de globalización. El desafío para las sociedades locales está 


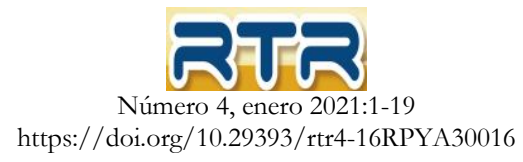

planteado en términos de insertarse en lo global de manera competitiva, capitalizando al máximo posible sus capacidades por medio de las estrategias de los diferentes actores en juego". (Gallicchio. 2004 p, 4)

De la misma manera, el desarrollo local es una estrategia de desarrollo a nivel espacio temporal concreto, que combina procesos de organización y de acción colectiva, con procesos de creación de significaciones (cultura Local) redes sociales y política de democracia e inclusión social, y de generación de capacidades de gestión ya sean sociales y productivas. (Contreras, 2000 p, 56)

Los gobiernos locales son los más legitimidados, articulando la intervención de los actores territoriales entregando un aprendizaje proactivo y emprendedor. Por lo que es de suma importancia asumir su papel de liderazgo local para animar procesos de movilización y participación de actores locales. (Alburquerque, 2003 p, 15)

\section{La política pública de inclusión laboral.}

En Chile con la promulgación de la Ley 19.284 de Integración Social de las PcD, comienza un cambio en la legislación para obtener un país más inclusivo. Desde la ratificación de la convención de los Derechos Humanos para las PsD y sus protocolos facultativos por Chile en el año 2008, se comienza la creación de políticas que a través de planes y programas vayan en apoyo de las PsD, luego de una lucha por ser escuchados y hacer valer sus derechos como sujetos.

En el año 2010 se promulga la Ley $\mathrm{N}^{\circ} 20.422$, creando el Servicio Nacional de Discapacidad (SENADIS) quien está bajo la dirección del Ministerio de Desarrollo Social, con la finalidad de construir un país más igualitario en condiciones para las PsD. Trayendo con ella, una serie de decretos que acceden a normar la accesibilidad. Esta ley en su primer artículo establece la norma sobre igualdad de oportunidades e inclusión social de personas con discapacidad, con el fin de obtener su plena inclusión social, asegurando el disfrute de sus derechos y eliminando cualquier forma de discriminación fundada en la discapacidad. (Art. 1)

En Chile la discapacidad luego de la ratificación de los derechos humanos, se promulga la ley $\mathrm{N}^{\circ}$ 20.422 basada en el marco universal de cultura y respeto de los derechos humanos de las personas con discapacidad, recogiendo el paradigma en materia de discapacidad, induciendo al cambio desde una mirada del Estado con su rol asistencial a un enfoque centrado en la persona, sus derechos y fomentando la independencia y autonomía.

Posteriormente, se promulgan otras leyes en esta temática, que tienen por generalidad la adecuación normativa como la Ley $\mathrm{N}^{\circ} 20.940$ que tiene por objeto la modernización en el tema laboral en materia de discapacidad y a la no discriminación, la Ley $\mathrm{N}^{\circ} 20.957$, esta consta de que PsD pueden tener cargos importantes como juez o notario, la Ley $\mathrm{N}^{\circ} 20.968$, aquí tipifica delitos de tortura y de tratos crueles, la Ley $\mathrm{N}^{\circ} 20.978$, esta es en relación al deporte, donde el Estado debe proveer de condiciones facilitadoras para el desarrollo físico y deportivo y la Ley $\mathrm{N}^{\circ} 21.015$, la nueva ley en materia de inclusión laboral. (Biblioteca Del Congreso Nacional, (BCN))

Esta última ley, que cobra vigencia en el año 2017, en su artículo 157 que señala que las empresas por cada 100 trabajadores deberán contratar o mantener contratados, según corresponda el 1\% de personas con discapacidad o que sean asignatarias de una pensión de invalidez de cualquier régimen. Haciendo mención aquellas empresas que por razones fundadas no puedan contratar, deberán cumplir con celebrar contratos de otro tipo de prestaciones o de efectuar donaciones en dinero a proyectos o programas a corporaciones o fundaciones según la Ley n ${ }^{\circ}$ 19.885. (BCN) 


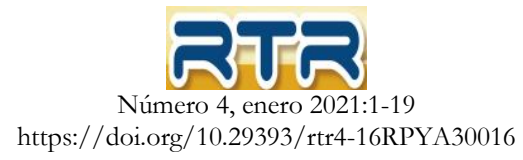

"Con el fin de reducir la pobreza, crear nuevos puestos de trabajo ayuda al progreso económico y social, los actores locales promovieron iniciativas como respuesta de las localidades y territorios a los desafíos que platean el ajuste productivo y la creciente competencia en los mercados nacionales e internacionales". (Vásquez, 2007, p, 1)

Gráfico 24: Tasa de participación laboral de la población adulta por situación y grado de discapacidad

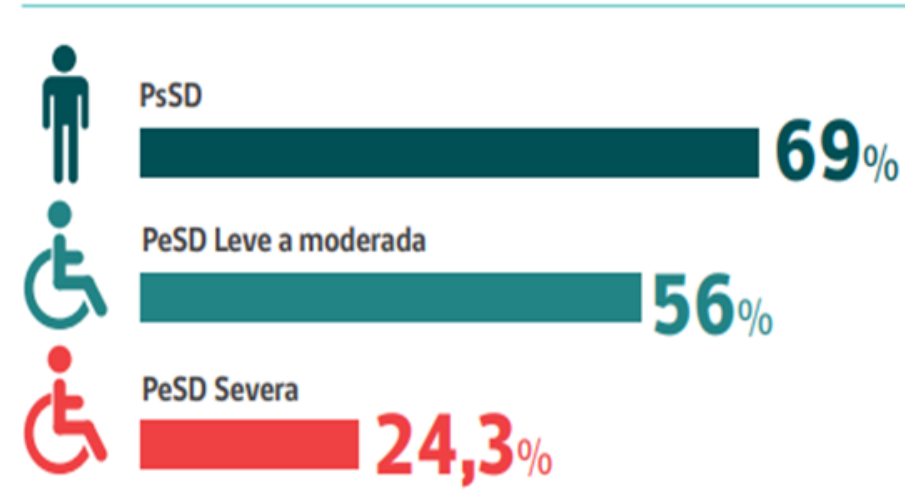

Ilustración 3 II Estudio de Discapacidad 2015

Actualmente el municipio trabaja bajo el lineamiento del SENCE, a través de la Oficina de Intermediación Laboral (OMIL), quien cuenta con el nexo de las empresas de la comuna y de un registro de personas en busca de trabajo. Por este medio, las empresas solicitan según su necesidad y el perfil para el cargo o vacante que necesita ser ocupado.

OMIL en conjunto con la Oficina de Discapacidad, mantienen un nexo con la gran mayoría de las empresas locales, para poder cumplir con la normativa de la ley, donde en algunas ocasiones, cumplir con la cuota mínima es difícil, sobre todo en tiempo de temporada, existiendo la posibilidad de gestionar con algún trabajador que tenga alguna limitante, que permita la acreditación de alguna discapacidad. Las empresas por lo general necesitan a personas con discapacidad leve o moderada, para el rinde de su productividad o por no contar con las normas de accesibilidad adecuadas.

Como institución pública, La oficina de discapacidad, bajo coordinación de la cabeza regional, alcanza a cumplir con una ejecución de manera parcial, mayoritariamente lo que pasa en el mundo rural al igual que en otros comunas no alcanza a contar con los estándares mínimos para cumplir con un buen desarrollo de política de inclusión.

El contar con una política que solo brinda un conjunto de acciones y prestaciones sociales que con otros órganos del Estado permiten contribuir de manera directa e indirecta a buscar la igualdad de oportunidades, a la inclusión social, la participación y accesibilidad de las personas en situación de discapacidad, no logran por completo promover el desarrollo de acciones que favorezcan la coordinación de aquellas materias que vayan en relación con mejorar la calidad de vida de las personas con discapacidad.

Estructuralmente la política de inclusión, en un análisis, no responde finalmente a una política pública de discapacidad real, ya que se estructuran desde el nivel central donde no se cuenta con la realidad de las comunas, tomado en cuenta el mundo de la ruralidad, no logrando impactar y dar solución a las necesidades de los gobiernos locales en tema de inclusión. 


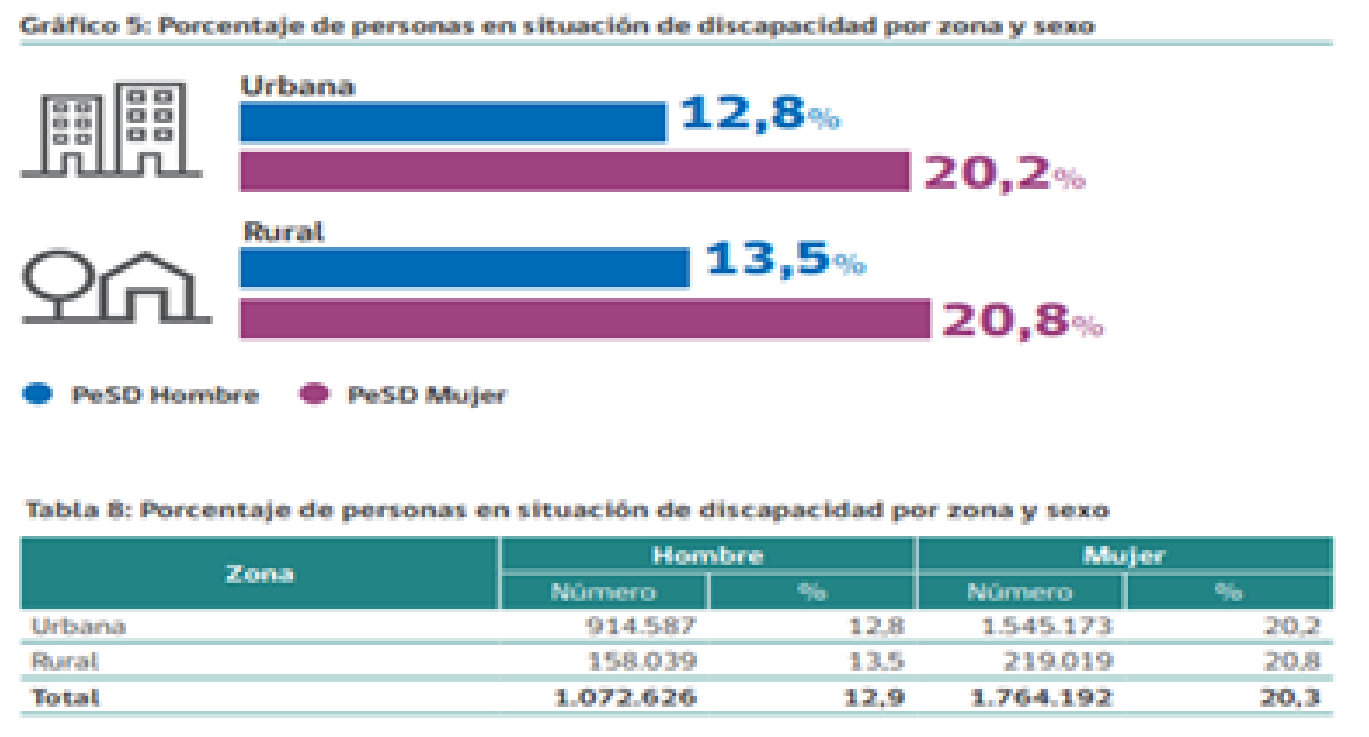

Por lo que conocer la percepción de los sujetos, permite de mejor manera conocer el sentir y a la ves las necesidades, donde ellos expresan el "yo pienso, yo sé, y yo creo", donde sus contenidos representan sus opiniones de información o creencia y podemos decir que una participación real se presenta concretamente como un complejo indiferenciado de elementos cognitivos relativos a un objeto social" (Ávila, Carmen, Gil, Lida, López, Vélez, 2012, pág., 25). De tal manera, que así poder lograr una política local, más atingente a las necesidades y realidades de la comuna, donde los mismos sujetos, PsD, sean los actores principales en la política local en temas de inclusión laboral, puede ser más propicia a las reales necesidades de las PsD.

\section{La participación ciudadana y su involucramiento}

El promover la participación es muy importante, de manera de lograr empoderar a los actores y se hagan partícipes de impulsar el cumplimiento de las políticas públicas en temas de discapacidad.

Para ello Contreras y Montecinos (2019), atreves de un estudio descriptivo de diversas publicaciones señalan al respecto que existen diversos modelos y enfoques de participación donde los ciudadanos pueden identificar mecanismos para lograr una experiencia que permita obtener las mejores herramientas que sean utilizadas para lograr una mejor participación. (p, 4)

Para llevar a cabo este propósito, los actores de la sociedad civil, son quienes conocen la realidad y problemas que son necesarias de resolver, asignando a ellos la responsabilidad de ser participe en la toma de decisión o en la búsqueda de solución en conjunto con el gobierno local y los demás actores, para obtener resultados positivos.

La comuna de Romeral, actualmente se encuentra construyendo el Consejo Comunal de Organizaciones e la Sociedad Civil, (COSOC). Con la implementación del COSOC, se pretende impulsar mayor movilización en la comunidad representada por los dirigentes de las diversas organizaciones civiles, donde las $\mathrm{PsD}$, también sean partícipes, opinando y dando a conocer sus realidades y necesidades de su grupo a la comunidad y al gobierno local.

Si bien la percepción de los COSOC, en otras comunas, no ha logrado un impacto en la participación, siendo ésta deliberativa, que no logra movilizar a la comunidad, existen los debates consultivos y donde los alcaldes son quienes nombren a los representantes en su mayoría. Esto debido 


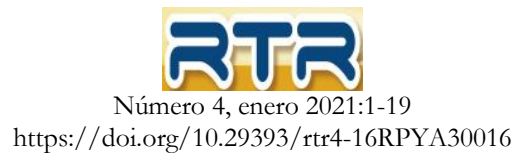

a que la gobernanza muchas veces se ve truncada en su implementación por cambios en la administración y la ciudadanía se frustra al ver que su participación no es efectiva (Valenzuela, Toledo, Muñoz, 1998 p, 3-18)

Contreras y Montecinos (2019), analizan como es asignada la participación ciudadana según la democracia en el enfoque prescriptivo y descriptivo, además de los modelos representativos, participativos, deliberativos y radicales. ( $($, 5) Estos enfoques y modelos permiten observar como es la construcción de la realidad según el punto de vista o como es observado cada uno de ellos.

Prescriptivo: se caracteriza por describir la construcción ideal del autogobierno del pueblo. Con un rol resolutivo y transformador de los conflictos, con espacios de diálogos discursivos, para la interacción comunicativa y la suceso en la toma de decisiones.

Descriptivo: sistemático, que hace relación a la experiencias, las características que han dado forma a las democracias. Tiene por objeto que la sociedad participe en los mecanismos ya existentes, como son los procesos de elección.

En cuanto a la democracia representativa, participativa, ambas por si mismas logran ser autosuficientes. Las representativas participan o restringe a la participación ciudadana de las elecciones al elegir un represéntate político. En tanto la participativa va de frente con la crítica y a su vez se complementan ambas, y fomenta el desarrollo humano al lograr dar respuesta a los problemas colectivos que contribuye a una ciudadanía activa y sabía. ${ }^{1}$

La deliberativa aglomera pretensiones de la participativa y radical, articulándolas. La primera articula y dialoga desde la crítica y activa, así lo plantean los autores, haciendo mención a Habermas. La representativa escucha los discursos públicos y codifica los mensajes. En cuanto a la radical es liberal y hace responsable al ciudadano de conducir los procesos frente a las demandas creando estos espacios públicos.

Hablar de todas ellas, es articular la voluntad popular, a través de la comunicación donde los ciudadanos participen y logren equilibrar, a través del proceso comunicativo, la racionalidad, equidad y honestidad en las negociaciones. (Ibis)

El poder crear alianzas o redes con instituciones no gubernamentales, empresas y en conjunto con la ciudadanía, a través de un tripartito, logren de manera adecuada tomar las mejores decisiones para lograr resolver los problemas del territorio, para un mejor desarrollo local, sin dejar de lado la inclusión de las PsD.

Por lo tanto, Valenzuela y Yévenes (2015), señalan que "las fuerzas pro descentralizadoras desafían a los poderes centrales y las fuerzas sociales nuevas a los poderes tanto nacionales como provinciales, cuando estos cooptan o no hacen políticas de transformación en favor de los sujetos sociales". (p, 473) Es importante dar fuerza a la ciudadanía para que no sigamos solo con políticas de los niveles centrales, sino logremos poner en marcha políticas locales que permitan el desarrollo integrativo local y la participación de la ciudadanía, para disminuir la monopolización de la autoridad de unos pocos.

"En Chile son enormes las limitaciones a los municipios, que obligan a coordinarse con otros entes o buscar vías alternativas para poder actuar... "red de gobierno local" en ese problema específico, para así salir del callejón sin salida." (Valenzuela, 1996. p, 1)

La construcción de la política pública busca que la política social "trascienda los planes y políticas gubernamentales que haga realidad la descentralización y que, mediante procesos participativos intersectoriales, se ubique el real estado de necesidades, usuarios, propuestas de acción, compromisos" (Ávila, Carmen, Gil, Lida, López, Vélez,

\footnotetext{
${ }^{1}$ Lo expuesto en estos párrafos es una pincelada de varios autores nombrados por Contreras y Montecinos, en cuanto a los enfoques de la democracia y sus modelos. Ellos señalan que la participación es importante para cada ciudadano, donde muchas veces priman la desigualdad económica y social, y carecen de recursos y oportunidades. Por lo que una participación activa en la vida política y social, se vuelven limitadas. Muchas veces tanto en el ámbito local como en el trabajo. Por lo que una participación genuina se ve escaseada de voluntades.
} 
2012, pág., 465) lo que busca la política pública es poder entregar mayor autonomía a los gobiernos locales, para conocer a través de la participación y opinión de los sujetos las necesidades propias, porque las necesidades de este grupo, son heterogéneas y dependiendo el contexto geográfico los requerimientos de las personas rurales son distintos a los requerimiento de las personas en localidad urbano.

\section{Una mejora en la política pública de inclusión aboral}

La actual situación en Chile y en nuestra comuna, nos muestra que existe una política pública que si bien tiene pertinencia no cumple con la factibilidad y la sustentabilidad, esto debido a que las políticas públicas en general, son sustentadas desde el Estado, quien no conoce la realidad de las diversas comunas, siendo todas ellas heterogéneas, inclusive en sí mismas.

Hoy la necesidad manifiesta que la existencia de una ley, no da por completo los resultados a la población de $\mathrm{PsD}$, por lo que es muy importante, comenzar a conocer las realidades desde los actores, para poder lograr los cambios necesarios en cuanto a la inclusión laboral.

Para ello, se debe constar con una sustento económico, primeramente desde las arcas municipales, para logra asegurar presupuesto para la continuidad de la política local, y en la medida que la política local se desarrolle, poder contar con mayor presupuesto que puedan ser asignados desde el fondo regional a través de proyectos, por lo que la clave en esta política, es la estrategia entre una alianza socioeconómica, también con los actores productivos locales, para que sea una buena práctica y que sea capaz de atraer mayores recursos a la comuna.

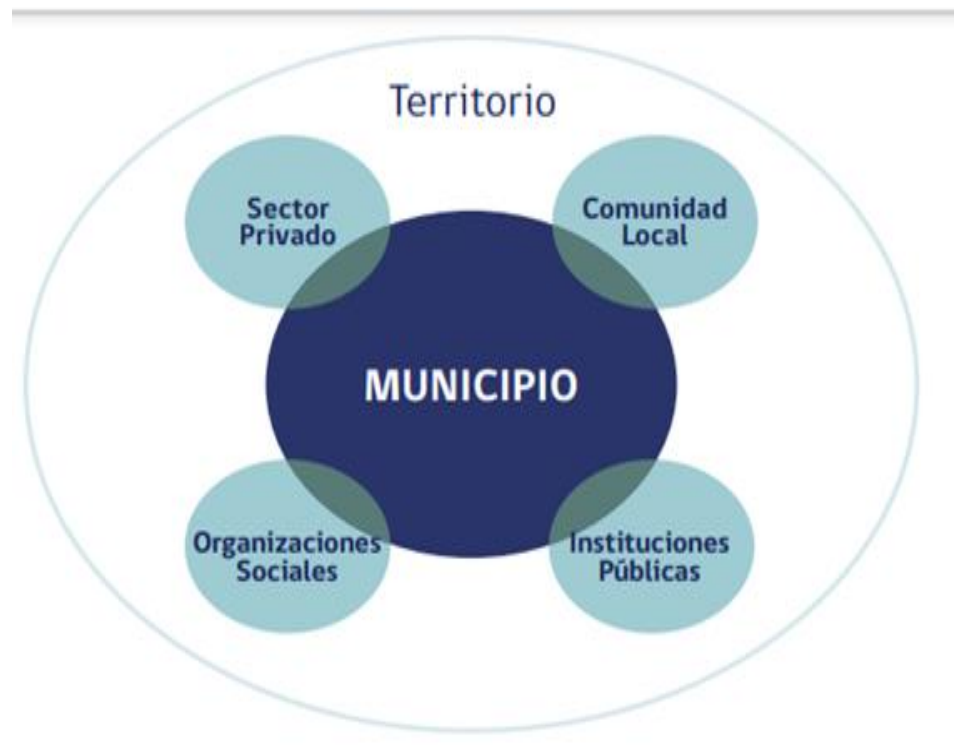

Ilustración 5Buenas Prácticas Inclusivas 2017-2018

Objetivo general: Aumentar los puestos de colocación laboral con capacitación a las personas en situación de discapacidad de la comuna de Romeral, con la participación y apoyo de las empresas locales. 
Objetivos secundarios: Crear una mesa de diálogo con propuestas de trabajo colaborativo, en conjunto con los actores principales.

Promover la contratación de PsD en la comuna, con la creación de puestos específicos según el perfil de la persona.

Hacer alianzas entre las comunas con entidades privadas, para la capacitación de PsD.

Crear una cooperativa en los actores relevantes, para aportar al desarrollo local y a la contribución de trabajos dignos.

\section{Principales problemas de la política}

Como se ha mencionado a lo largo de este apartado, existen falencias de porque la política pública no responde a las verdaderas necesidades de las PsD, sino más bien solo a cumplir con una cuota para responder ante las normativas legales en que Chile ha creado.

Entre estas falencias se encuentran la desinformación y escasa accesibilidad, la nula participación de las PsD en temas de inclusión, descontinuación de un proyecto impulsivo para potenciar a la comuna en discapacidad, y la no existencia de una mesa de trabajo en materia de discapacidad.

\section{Desinformación}

En cuanto a la desinformación de los diversos actores, solo conocen de la ley que debe existir un cumplimiento mínimo, del cual la gran parte de las empresas contratan a PsD, que cuenten con alguna discapacidad leve o moderada. Las empresas, generalmente no inyectan recursos en capacitar o adecuar los espacios, sino solo, con lo mínimo para cumplir con las normas. Por lo que, la pobreza se centra en las PsD, porque no cuentan con nuevas oportunidades y las pensiones, son ingresos insuficientes para sustentar a una familia. Tampoco, optan por la donación, además de no contar con entidades locales donde ellos puedan dirigir estas donaciones.

En cuanto a las condiciones de accesibilidad, las empresas cuentan con una infraestructura muy baja que permita la contratación de PsD con mayores requerimientos como en silla de rueda, por no contar con baños adecuados, espacios muy reducidos y uno que prioriza, es que las empresas priman la productividad por sobre todo.

Aquí, la importancia de contar con el personal adecuado de la oficina de discapacidad, que solo se ocupe de la función del trabajo en temas de inclusión laboral, para poder marcar presencia en las empresas y lograr acuerdos, además de informar y tener un registro específico de las PsD y sus condiciones físicas para ejercer funciones laborales. Además de informar y educar a las PsD, que no se manejen o desconozcan por completo la ley de inclusión.

\section{Nula participación en temas de inclusión}

Si bien las PsD, cuentan con grandes organizaciones, en la comuna solo existen dos grupos, de los cuales uno no mantiene activo su grupo, y el otro, son pacientes de la sala de rehabilitación del CESFAM de la comuna, que mayoritariamente realiza actividades deportivas, entre otras, pero que no lograron sacar adelante su proyecto de hierbas medicinales, por no contar con una continuidad o asesoramiento para ello. Esto quiere decir, que no se han involucrado en temas de proyectos, y como ellos agrupados pueden hacer publica sus necesidades de forma de dar a conocer a la comunidad de sus falencias como sujetos de derecho, y lograr expandir esta invitación mas PsD, de manera de crear un grupo número que relevante la voz en la comuna y comiencen a dialogar respecto a los temas de inclusión. 
También es importante contar con un apoyo desde la oficina de discapacidad, en el ámbito sociocomunitario, para hacer más participes a las $\mathrm{PsD}$, y que puedan implementar diálogos participativos, focos group, entre otros instrumentos, que logren identificar porque no existe la participación y generar instancias de acercamiento y participación con la comunidad.

\section{Mesa de trabajo intersectorial}

Este es uno de los puntos más importantes dentro de la comuna, el que no exista una mesa comunal de discapacidad para conocer en primera instancia la realidad específica de la comuna en cuanto a discapacidad.

Esta mesa permitirá poder contar con actores de las diversas áreas, tanto gubernamentales, de la sociedad civil, empresarial, entere otro, para poder crear una alianza que permita dar respuesta a una política pública más inclusiva en el tema laboral y en otros aspectos de la vida de las PsD.

El conocer la realidad, permitirá tomar decisiones acordes a las necesidades laborales y de las $\mathrm{PsD}$, como en poder fortalecer alianza con otros actores o comunidades, que apoyen la gestión de la integración al mundo laboral, para hacer la distinción entre una contratación de PsD a un trabajo que satisfaga de manera personal dignificando a las PssD.

Además, para lograr lo señalado, existe la voluntad política del gobierno local, pero si es necesario mayor compromiso, de los diversos actores, así también contar con recursos para comenzar y lograr que la política se lleve a cabo, y posteriormente desde el nivel regional, para el apoyo y el logro de aumentar los puntos de trabajo según las necesidades o requerimientos que se dé al ejecutar la política local.

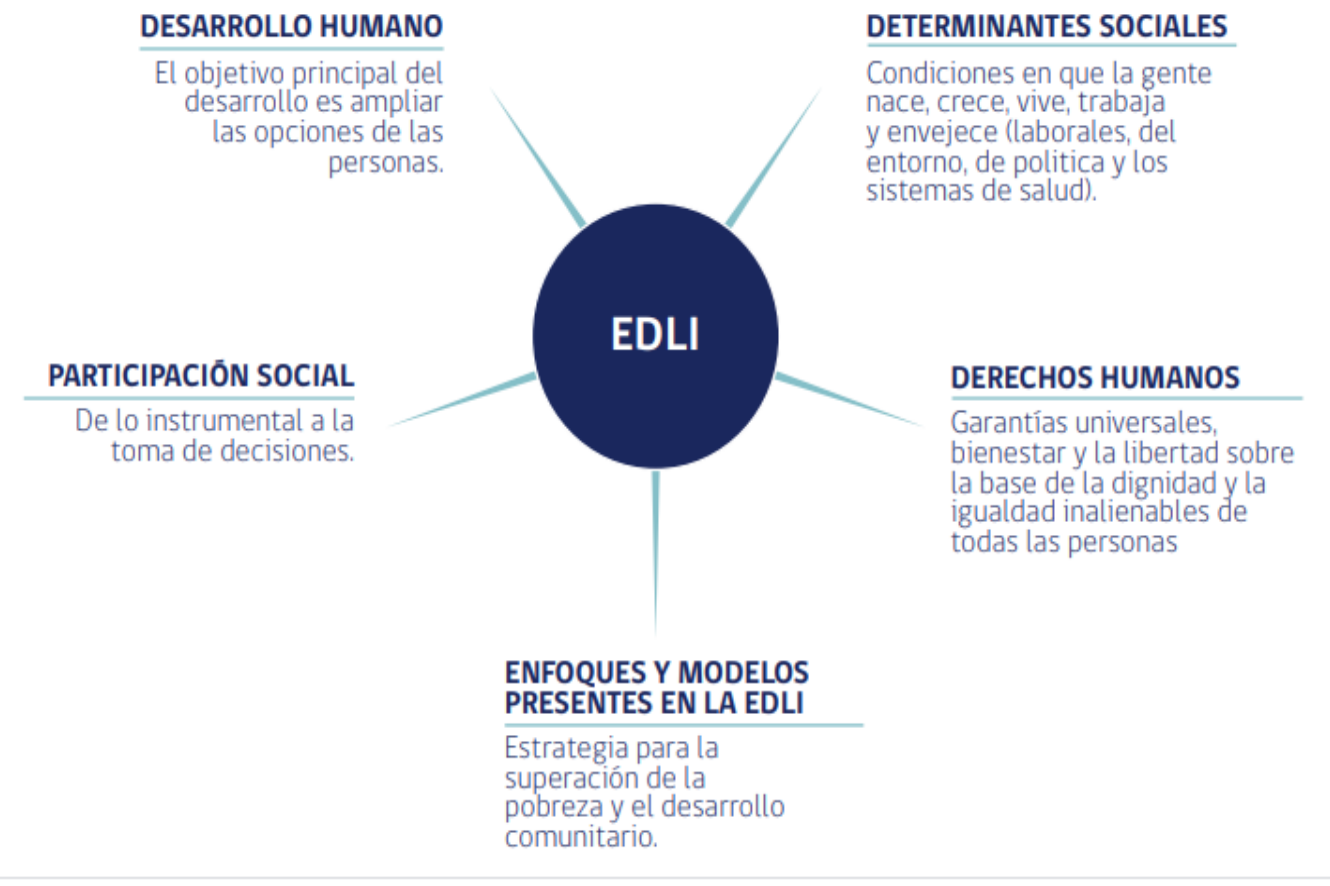

Esta política pública la cual debe contar con tres requisitos: tener pertinencia, factibilidad y sustentabilidad. 
1.- lograr que el $50 \%$ de las empresas que existan en la comuna sean partícipes de la mesa comunal de discapacidad, a una proyección de 5 años.

2.- lograr que en un 50\% de las empresas constituyentes de la mesa incluyan en sus gastos capacitación para $\mathrm{PsD}$, a una proyección de 5 años.

3.- Aumentar en un 30\% la contratación de PsD en funciones laborales específicas según el perfil de la persona.

4.- Aumentar la participación de los actores relevantes en un 50\% para crear una cooperativa que aporte al desarrollo local y personal de PsD.

\begin{tabular}{|c|c|c|c|c|c|}
\hline Calendarización & Año 1 & Año 2 & Año 3 & Año 4 & Año 5 \\
\hline $\begin{array}{c}\text { Trabajo en } \\
\text { conjunto con } \\
\text { las empresas }\end{array}$ & $\mathrm{X}$ & $\mathrm{X}$ & $\mathrm{X}$ & $\mathrm{X}$ & $\mathrm{X}$ \\
\hline $\begin{array}{c}\text { Creación de la } \\
\text { mesa sectorial } \\
\text { en tema de } \\
\text { discapacidad }\end{array}$ & $\mathrm{X}$ & $\mathrm{X}$ & $\mathrm{X}$ & $\mathrm{X}$ & $\mathrm{X}$ \\
\hline $\begin{array}{c}\text { Reuniones } \\
\text { mensuales para } \\
\text { planificación de } \\
\text { la mesa }\end{array}$ & $\mathrm{X}$ & $\mathrm{X}$ & $\mathrm{X}$ & & \\
\hline $\begin{array}{c}\text { Crear alianza } \\
\text { con ONGs que } \\
\text { realicen } \\
\text { capacitaciones }\end{array}$ & $\mathrm{X}$ & $\mathrm{X}$ & $\mathrm{X}$ & & \\
\hline $\begin{array}{c}\text { Implementar o } \\
\text { adecuar la } \\
\text { infraestructura } \\
\text { en las empresas } \\
\text { para }\end{array}$ & $\mathrm{X}$ & & $\mathrm{X}$ & & \\
$\begin{array}{c}\text { contratación de } \\
\text { PsD }\end{array}$ & & & & & \\
\hline $\begin{array}{c}\text { Comprometer a } \\
\text { la formulación } \\
\text { de proyectos } \\
\text { para la creación } \\
\text { de una } \\
\text { cooperativa en } \\
\text { la comuna }\end{array}$ & & & & & \\
\hline
\end{tabular}

\section{Actores sociales}

Los participantes o actores sociales que forman la estrategia sociocomunitario para el cumplimiento de la política pública, son quienes tienen un rol importante para la implementación de esta, siendo mencionados a continuación.

-Alcalde 


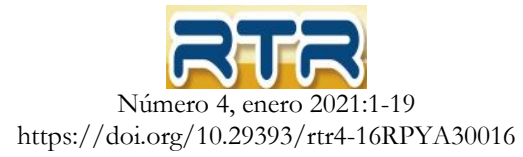

-Concejales

-Encargada Oficina Comunal de Discapacidad

-Unión Comunal de Junta de Vecinos

-Agrupación de Personas en situación de Discapacidad

-Comunidad civil

-Cámara de comercio

-Asociaciones de productores

-Empresas frutícolas

-Pymes

-Salud

-Educación

-Registro Civil

Hay que tener en claro que también se puede contar con la participación a nivel central y regional como Servicio Nacional de Discapacidad y El Ministerio de Desarrollo Social.

\section{Comunas que cuentan con políticas locales inclusivas}

A través de los diagnósticos participativos la EDLI reconoce la realidad de una comuna, mediante la participación local y como esta se une a las redes existentes en la comuna.

En el año 2017 dentro de la estrategia de la EDLI, esta fue implementada en la comuna de Teno, contando con un proyecto inclusivo que motiva a la participación de los espacios de partición ciudadana. Un gran apoyo para la implementación de este proyecto es el apoyo de las familias, donde ellos también se hacen participes.

En la ciudad de Quillota, continúo con el lineamiento de la EDLI, por lo que su propuesta fue la creación de alianzas estratégicas con empresas, que necesitaran puestos específicos y capacitar a las PsD, para estos puestos. Además contaron con el nexo de las instituciones en la comuna, como institutos profesionales, quienes capacitan a las PsD, para estos puestos.

Posteriormente se realiza un proceso de acompañamiento durante la adaptación de la PsD en sus funciones labores y luego se realizan visitas periódicas para ver el cumplimiento de la función y de la empresa, con la finalidad de que no deserten de los puestos de trabajo.

En Curicó, comuna más cercana a Romeral, la Cooperativa HIMACOP Hijos de María, cuenta con la creación de una cooperativa, donde trabajan de manera independiente, con discapacidad cognitiva, cuentan con un taller de estampado de tazones, bolsas reciclables, poleras. Otro taller con el que cuentan es de masoterapia, saliendo a las empresas a realizar masajes relajantes. Ellos cuentan con el convenio con SENADIS y CIESCOOP USACH para el desarrollo de esta en su formación y capacitación, con el objeto de una mejor y efectiva inclusión laboral.

\section{Nudos Críticos y conflictos.}

Hay que tener en claro, que cada comuna es diversa, por lo que cada ejemplo o resultado de una política no es igual a otra comuna. En algunas localidades han tenido grandes resultados y buenas alianzas estratégicas que han permitido la continuación y una excelente inserción laboral para las PsD. Pero claramente, en otras localidades, aún no cuentan con Oficinas de discapacidad que les permita crecer en estas iniciativas para el desarrollo local inclusivo.

\section{Principales fuentes de Financiamiento}




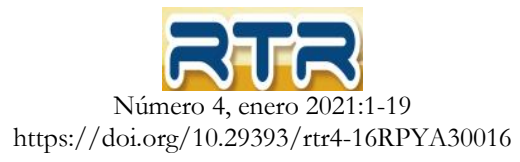

Las cooperativas cuentan con el apoyo del financiamiento de SERCOTEC quienes apoyan al micro y pequeñas empresas en sus emprendimientos, para su desarrollo y crecimiento en el país y a nivel local. Esta cuenta con diversas líneas de financiamiento.

Dentro de estas líneas de financiamiento también se encuentra CORFO, quien a mayor escala, es un organismo multisectorial, fomentando la producción nacional y promotora de crecimiento económico regional. También cuenta con diversos programas que apoyan a diferentes organizaciones.

También existe FOSIS, Fondo de Solidaridad e Inversión Social, dependiente del Ministerio de Desarrollo Social, cuyo objetivo es la superación a la pobreza y vulnerabilidad de personas, familias y comunidades, apoyando también las líneas de acción de las cooperativas inclusivas.

$\mathrm{Y}$ entre estas fuentes de financiamiento se encuentra SENADIS, quien tiene por objeto promover la igualdad de oportunidades, la inclusión social, participación y accesibilidad de las PsD. Su línea de acción en apoyo a las cooperativas es el Fondo Nacional de Proyectos Inclusivos FONAPI, donde postula entidades públicas o privadas sin fines de lucro, financiando diversas iniciativas.

En cuanta a capacitación, las empresas cuentan con un porcentaje de sus tributos, por medio de las franquicias tributaria, así también se cuenta con ONGs que a través de proyectos, capacitan, por lo que habría que identificar cuales se desempeñan en esta área y por otra parte el Servicio Nacional de Capacitación y empleo (SENCE), sería otra línea para el apoyo en capacitación a trabajadores con Discapacidad, en oficios o funciones específicas.

\begin{tabular}{|l|l|l|l|}
\hline actores & Indicadores & hito & Costo \\
\hline Alcalde - concejales & $\begin{array}{l}\text { Facilitar en un 100\% } \\
\text { infraestructura para las } \\
\text { capacitación y } \\
\text { reuniones }\end{array}$ & $\begin{array}{l}\text { Acto de entrega de la } \\
\text { infraestructura para las } \\
\text { actividades }\end{array}$ & $\begin{array}{l}\text { Mantención, limpieza, } \\
\text { servicios básicos } \\
\text { M\$5.000.- }\end{array}$ \\
\hline $\begin{array}{l}\text { Encargada oficina } \\
\text { comunal }\end{array}$ & $\begin{array}{l}\text { Disposición en un } \\
100 \% \text { Encargada }\end{array}$ & $\begin{array}{l}\text { Oficina equipada para } \\
\text { asesor a las personas } \\
\text { en discapacidad }\end{array}$ & $\begin{array}{l}\text { Costo oficina por parte } \\
\text { del municipio } \\
\text { M\$10.000.- }\end{array}$ \\
\hline $\begin{array}{l}\text { Unión comunal } \\
\text { APSD }\end{array}$ & $\begin{array}{l}\text { Trabajar en un 100\% la } \\
\text { inserción laboral a } \\
\text { personas en situación } \\
\text { de discapacidad }\end{array}$ & $\begin{array}{l}\text { Personas inscritas, } \\
\text { capacitadas, apresto } \\
\text { laboral. otras }\end{array}$ & $\begin{array}{l}\text { Pesquisa, compromiso, } \\
\text { capacitación, } \\
\text { seguimiento } \\
\text { M\$2.000.- }\end{array}$ \\
\hline $\begin{array}{l}\text { Cámara de comercio } \\
\text { Asociación de prodc. } \\
\text { Empresas y pymes }\end{array}$ & $\begin{array}{l}50 \% \text { de Personas en } \\
\text { situación de } \\
\text { discapacidad } \\
\text { contratadas }\end{array}$ & $\begin{array}{l}\text { Postulación a puestos } \\
\text { de trabaja a personas } \\
\text { con habilidades } \\
\text { diferentes }\end{array}$ & $\begin{array}{l}\text { Inducción en el puesto } \\
\text { de trabajo mayor } \\
\text { tiempo } \\
\text { M\$2.000.- }\end{array}$ \\
\hline Salud / educación & $\begin{array}{l}\text { Articular en } 100 \% \text { las } \\
\text { redes de personas } \\
\text { atendidas de estos } \\
\text { programas }\end{array}$ & $\begin{array}{l}\text { Programa de inserción } \\
\text { laboral con apresto } \\
\text { labora, atención en } \\
\text { salud en horarios no } \\
\text { laboral }\end{array}$ & $\begin{array}{l}\text { Equipamiento y } \\
\text { trabajo de } \\
\text { profesionales en trato } \\
\text { especial } \\
\text { M\$10.000.- }\end{array}$ \\
\hline
\end{tabular}

Conclusión 


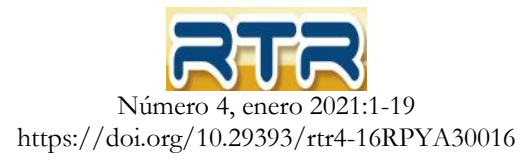

Una política local más inclusiva con la participación de la ciudadanía y de los actores de la sociedad civil y gubernamentales, hacen fortalecer una comuna, entregando dignidad, derechos e integración a las personas con discapacidad, donde ellos son y deben ser los propulsores de las políticas frente a sus necesidades, especialmente en el mundo laboral.

La discapacidad es una barrera que la sociedad aún no ha logrado derribar, y desconocen todo lo que encierra la palabra discapacidad.

Como se expuso en los párrafos escritos, existen buenas instancias de participación para implementar una política que a mediano y largo plazo pueda dar frutos y ser significativa para las PsD, logrando con ello su autonomía, independencia, ingresos y un cambio en la manera de ver la discapacidad como sujetos de derechos y no como objetos de caridad.

\section{Bibliografía}

Ávila Rendón, Carmen; Gil Obando, Lida; López López, Alexandra; Vélez Álvarez, Consuelo (2012) Políticas públicas y discapacidad: participación y ejercicio de derechos. Investigaciones Andina, vol. 14, núm. 24, pp. 457-475 Fundación Universitaria del Área Andina Pereira, Colombia Recuperado el 9 de noviembre 2020, de https://www.redalyc.org/pdf/2390/239024334008.pdf

Alburquerque, Francisco (2006) Teoría y práctica del enfoque del Desarrollo Local. (Chile) Instituto de Economía y Geografía, Consejo Superior de Investigaciones Científicas. pp. 1-24 Recuperado en 15 de noviembre 2020, de

https://pdfs.semanticscholar.org/38aa/adb237c1057f9160b31374c 7826468b82875.pdf? ga=2.2544963 28.1149239468.1584929973-149742925.1584822723

Biblioteca del Congreso Nacional www.bcn

Contreras, Rodrigo. (2000) Empoderamiento Campesino y Desarrollo Local. Revista Austral de

Ciencias Sociales. Núm. 4 pp. 55-68 Recuperado en 10 de noviembre 2020, de

http://revistas.uach.cl/pdf/racs/n4/art03.pdf

CONTRERAS, P., \& MONTECINOS , E. (2019). Democracia y participación ciudadana: tipologia y mecanismos para la implementacion . Ciencias Sociales . Revista de ciencias sociales, ISSN-e 13159518, Vol. 25, No . 2, 2019, págs. 178-191 Recuperado en 10 de noviembre 2020 de

https://dialnet.unirioja.es/servlet/articulo? $\operatorname{codigo}=7026001$

El Rol de los Gogiernos Locales en el Desarrollo Económico Territorial, $5^{\circ}$ Congreso de Cumbre Mundial de Líderes Locales Y Regionales. Recuperado en 10 de noviembre 2020 de

https://www.uclg.org/sites/default/files/el_rol de los_gobiernos_locales en el desarrollo_economi co territorial.pdf

Gallicchio, Enrique (2004) El desarrollo local en américa latina. Estrategia política basada en la construcción de capital social pp., 1-24 Recuperado en 14 de noviembre 2020, de

https://flacso.edu.ec/cite/media/2016/02/Gallicchio-E 2004 El-desarrollo-local-en-America-Latina.Estrategia-politica-basada-en-la-construccion-de-capital-social.pdf 


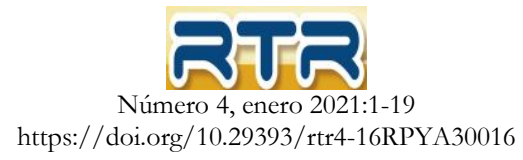

Padilla-Muñoz, Andrea. (2010).Discapacidad: contexto, concepto y modelos. Internacional Law: Revista Colombiana de Derecho Internacional, $N^{\circ}$ 16, pp., 381-414. Recuperado en 15 noviembre 2020, de http://www.redalyc.org/articulo.oa?id=824200012

Muyor Rodriguez, Jesús (2011) "La conciencia del Trabajo Social en la discapacidad: Hacia un modelo de intervención social basada en derechos", Revista de Trabajo Social y Acción Social. N²49, pp 9-33. Recuperada en 12 de noviembre 2020, de https://dialnet.unirioja.es/servlet/articulo?codigo=4111301

Ministerio de Desarrollo Social, Servicio Nacional de Discapacidad, 2013, Políticas Nacionales para la Inclusión Social de las Personas con Discapacidad 2013-2020. Recuperado el 16 de noviembre 2020, de www.senadis.gob.cl

Servicio Nacional de Discapacidad (SENADIS) www.senadis.cl

Vásquez, Antonio (2009) Desarrollo Local, Una estrategia en tiempos de Crisis. Universidad Autónoma de Madrid. Vol. 28 núm. 47 pp. 117-132. Recuperado el 10 de noviembre 2020, de

file://C:/Users/evrey/Downloads/Dialnet DesarrolloLocalUnaEstrategiaParaTiemposDeCrisis3620464.pdf

Valenzuela Van Treek, Esteban, \& Yévenes Arévalo, Paolo. (2015). Aproximación al concepto de cooptación política: la maquinaria presicrática y sus formas. Polis (Santiago), 14(40), 469-488. Recuperado el 09 de noviembre 2020 de

https://dx.doi.org/10.4067/S0718-656815000100022

Valenzuela Van Treek, Esteban, Toledo Alarcón, Claudia, Muñoz Aravena, Waleska, \& Villa Sepúlveda, Felipe. (2020). Tres dimensiones de la democracia territorial: directorios multiactor, consultas vinculantes y empoderamiento social en la región del Biobío. Revista iberoamericana de estudios municipales, (22), 125-153. Recuperado el 09 de noviembre 2020 de

https://dx.doi.org/10.4067/S0719-17902020000200125 